\title{
A Study of the TPR Method in the Teaching of English to Primary School Students
}

\author{
Tingting Shi \\ Shanxi Normal University, Linfen, China
}

\begin{abstract}
In order to use TPR teaching method effectively in primary school English class, this paper uses the experiment method, two groups of students from Experimental primary school in Hongdong County of Linfen City are selected as the experimental subjects. In the process of the experiment, one group of students are taught by the TPR teaching method, another group of students are taught by the common traditional teaching method. The data from this experiment shows that the TPR teaching method is a more effective method. On the basis of the above research, this paper comes to a conclusion that the use of TPR teaching method will greatly enhance the students' learning efficiency. Through the research of this paper, the author hopes to deepen teachers' understanding of the TPR teaching method, the teacher can use the TPR method to carry on the teaching in the class and help students to learn effectively.
\end{abstract}

Index Terms - English teaching, Total Physical Response(TPR), traditional teaching methods

\section{INTRODUCTION}

With the development of education internationalization, English education has been paid more and more attention. What's more, English has played an increasingly significant role in Chinese education. The teaching method used in an English classroom in China is crucial. And these teaching methods must be suitable for students' learning. TPR is a teaching method developed by Dr. James J. Asher. It has a high renown and an important impact in the foreign language teaching. This method encourages to teach language through physical actions, gestures, and commands. But this approach mostly stays at the lower grade of primary school. Most important of all, it is still not widely spread.

According to a survey and some of the primary school English teachers and students' reflection, some English classes in rural areas still use the traditional teaching method which is teaching-centered, students in the rural places learn English through mechanical memory. They could lose interest in learning.

In primary school English teaching, in order to use TPR teaching method effectively, the writer implements a teaching experiment in Experimental primary school of Hongtong County. TPR teaching method can arouse students' interest in learning English. At the same time, it can also catch students' attention quickly and establish a foundation for further learning.

In China, there are many different kinds of methods for teaching English. For instance, traditional method, task-based language teaching, the communicative approach, and TPR teaching method, etc. Of course, the choice of teaching methods has a direct impact on the teaching effect. TPR teaching method has a lot of advantages in learning English. On the one hand, it can catch students' attention quickly; on the other hand, it can create a relaxed environment to make the students learn English through physical activities. At the same time, it can also enhance their self-confidence and stimulate their desire to learn English.

This paper mainly focuses on the benefits of TPR method in the teaching of English to primary school students, through a comparative research on teaching between TPR method and traditional method. This paper aims to reinforce the ability of words and sentences in learning English. What's more, TPR teaching method can reduce the psychological burden of the learning process and build a happy environment in English class.

\section{LITERATURE REVIEW}

In this section, the author mainly introduces some related theories about TPR method and the definition of TPR method. And the author also illustrates some features, teaching patterns and researches abroad and at home.

\section{A. The Related Theories of TPR Method}

TPR teaching method is introduced in the late 1960s. It has a high renown and an important impact in the foreign language teaching. This paper discusses two theoretical foundations of TPR teaching method.

1. Linguistic Theories

As early as the century, it was put forward by Asher, after the observation of numerous foreign language teaching project, he found that understanding is the most basic skill before speaking. (Asher, 1993, p.98). As a matter of fact, as early as 1940, Arnold and Thompson, two experts in child psychologists, found that before children began to speak they had been able to understand some of the adults' complex speech. "Once they have internalized the complexity of the language, they have acquired a well spoken language, and the "physiological" mechanism of this acquisition will not 
disappear, and they will take the initiative to speak out a large number of languages". (Yu Zhenyou, 1992, p.25). As early as 1980s, Chomsky and some linguists have put forward Universal Grammar Theory. This theory holds that when the materials of input language are limited, and even when the material is not completely consistent with the grammar, students can understand what they hear. So in the TPR classroom, the teacher will not ask the students to repeat what the teacher said at once and nor do they expect the students to speak soon. And even if the student has an "attempt" to speak, the teacher will try to postpone the time they begin to say. (Wang Li, 2008,p33). The reason for this is that the TPR teaching method believes, listening and understanding should precede the speaking. If the students do not have enough understanding about what they heard, it is not possible to produce language output.

2. Psychological Theories

TPR teaching method takes a psychologist's point of view, namely "memory trace". The theory of "memory trace" thinks that the greater the track frequency and intensity of contact is, the stronger the memory connection is, the more easily it is recalled. (DeCecco, J. D, 1968,p.66). The complex instructions in the TPR teaching method are based on the simple instructions. The TPR teaching method, which is the "listen-act model" as main teaching method, involves a large number of body movements. It is a strong memory to express the understanding of the instructions in this way. It can improve the retention rate of the memory. The TPR teaching method absorbs the role of humanistic psychology in the study of effective factors. It is believed that good emotional communication between teachers and students can reduce the psychological burden of students and create a pleasant learning atmosphere. A student should not be forced to speak unless he has made a full preparation. Even when a student has made some mistakes in his speech, the teacher should take a tolerant attitude towards them. Students generally will be free to express themselves through action, when the student's sense of anxiety is reduced. When they overcome the shyness of speaking English and have a good mood, the efficiency of learning will be improved.

\section{B. Definition of TPR Method}

The Total Physical Response is abbreviated as "TPR". Total Physical Response is a language teaching method which is built around the coordination of speech and action. It is put forward by James J. Asher. On the foundation of Asher's own researches and theories on second language acquisition, he founds TPR method. He points out that we should integrate language with actions to teach English through Total Physical Response. At the same time, we should also develop a student's listening ability firstly, then the speaking.

Total Physical Response teaching method provides a more relaxed learning atmosphere for learners. So students can overcome the stress of speaking English. Teachers can also attempt to create beneficial conditions for students to learn. When the students' subjective initiation is activated, the teaching efficiency will be better, too.

\section{The Features of TPR Method}

TPR teaching method emphasizes the abstract thinking is based on the image thinking. We are different for the two hemispheres of brain function. The right one of two hemispheres is in charge of abstract thinking, however the left one is in charge of image thinking. (Zhu Chun, 2000, p.189). Thus, the method proposes that the teaching process should be kept in a real situation or close to reality. Students should perceive the world through the senses rather than relying solely on the full range of audio-visual mode.

From the perspective of language learning, at first, students need to improve the listening ability, then to improve speaking and writing ability. The specific characteristics of the TPR teaching method can be summarized as follows:

1) Taking listening as the leading activity in the classroom.

2) If they have done much preparation work, we should allow students to take part in activities.

3) Students should improve their comprehension ability through the body's response to language.

4) Teaching should pay more attention to meaning rather than form, so that students can reduce the tension.

5) It helps to cultivate students' real communicative competence.

6) After using TPR teaching method, students can maintain long-term clear memory after a period of time. It plays a significant role in primary learners' long-term memory.

7) It has a higher recall rate. TPR teaching method can make learners recall more often after gaining the knowledge.

\section{Teaching Patterns}

TPR teaching method is a student-oriented teaching method. Its teaching methods are diverse. Its teaching material is not only one single word, but also sentence. In a typical class of TPR method, most of the activities in the classroom use imperative sentences. There are some other activities in the class, for example, slide presentations and role plays. Some cases are designed by the teacher, such as in the library or in the classroom, or asking for something and then the students are asked to take actions. The slide presentation provides a visual theme for teachers to teach, instruct and ask questions. For example, "In the slide, what can you see?" Writing and reading can also be used to further strengthen the structure and vocabulary.

According to Asher's statement, there is no certain material at the beginning of the TPR class. As time goes by, the role of the material will become more important. For beginners, a TPR class requires the teacher's gestures, actions and sounds. Afterwards, the teacher can use the general items, for instance, rulers, pens and other tools. With the progress of curriculum, the teacher may want to use additional materials to support teaching, they may include pictures, text charts, 
slides and so on. (Asher, 1993,p.65). Asher creates a set of student kits that can be in some particular situations, such as the classroom and the station. If necessary, the students themselves can be set to the scene.

\section{Cardboard Pattern}

The teacher writes 26 letters on different boards. Every student has a card. Before the teachers call, the teachers should continue reading until the students remember them. Later, when the student hears the name of the card in their hands, they should answer "yes, here I am". Next, the students exchange their cards, in response to the teacher's call. In this way, the student can not only master the pronunciation of the letter, but also identify how to write the letter. Meanwhile, they can pay more attention to the learning process.

\section{Game Pattern}

Depending on the nature of students' psychological characteristics, they can not keep their attention a long time and not often listen to the teacher. In this way, a positive classroom atmosphere will enable some of students to interact with teachers and other students to maintain their attention. In this mode, the teacher can also design some of the relevant content of the game. For instance, in order to inspire students' English thinking, the teacher divides students into 2 groups. One group is "snow" or "winter", the other group is "rain" or "summer". These two groups stand face to face, they are three meters apart. In the group "snow" of the students throws a ball to the group "rain". Moreover, they shout "white" or other color words. The other side of the student cries out like a "white peach", which is white. Next, they throw the ball to a group of "snow" and shout a kind of color. And let them do it all the way. The teacher can judge by the time of rule or control which group is the winner, and then gives them some gifts or prizes.

This game can cultivate students' sense of English and English thinking in a relaxed and pleasant atmosphere.

\section{Competition Pattern}

Learners not only have a strong curiosity, but also are eager to go beyond others. Accordingly, any competitive activities can arouse their enthusiasm for learning English. Teachers can make the best of the psychological characteristics and cultivate their language skills in the game. For instance, the teacher can divide students into several groups. Every group has its own name. At the same time, every group also has its own slogan. There is another form of competition between boys and girls. Teachers can also organize the competition between individuals and teams, or between teachers and students. Competition can cause students to be highly emotional and make language learning more interesting.

\section{E. Current Situation of Researches Abroad and at Home}

There are different views on the research of TPR method at home and abroad. In 1969, Asher carried out 30 to 40 experiments. Through the observation and analysis of the TPR method in the teaching of Japanese, Russian and other languages, Asher pointed out "no matter how complicated the language is or how long the time interval is, the TPR method can make the students understand quickly" in The Total Physical Response Approach to Second Language Learning. (Asher, 1993, p.126). In addition, in some exercises, no matter what the students do or just watch what others do, they have no relationship. It is important that students should have the opportunity to express themselves through physical action. Asher tries to find out the reasons why the TPR method can promote understanding and improve memory. He excludes a number of factors that might affect the effect of TPR, such as location and sequence. Last but not least, Asher comes to the conclusion that the most important factor is the learner's physical action. Krashen describes the TPR method as a way to get linguistic knowledge in the realistic and meaningful language activities. (Krashen, 2009,p.59).

In our country, the research on the students' English teaching is carried out later than the foreign countries. The famous British educator Gong Yafu compiles an English teaching material for children which is called Total Physical Response English, to promote the application of the TPR teaching method in practical teaching.(Gong Yafu, 2002, p.52 ) Yu Zhenyou (1992) puts forward his opinions on the second language acquisition, the characteristics and advantages of the TPR teaching method. Zhong Jing, from the perspective of cultivating students' interest in English learning, combines with her own research and teaching practice, points out the TPR teaching method which can excite students' interest that learning English. (Zhong Jing, 2002, p.36) From the above research, we can know that many scholars in our country have discussed a lot about the application of TPR teaching method in English teaching, however, the practical and systematic studies are rare.

\section{Methodology}

In this section, the author carries out an experimental research on TPR teaching method. In this experiment, two groups of students are adopted different teaching methods, the TPR teaching method and the traditional method. Data from the teaching experiment and the results of classroom observation are analyzed in order to get the practical effect of TPR in the classroom.

\section{A. Research Questions}

The purpose of this paper is to analyze the application of TPR teaching method in English teaching. The goal of this research is to compare the effectiveness of the TPR teaching method as a judgment of its effect on traditional teaching methods when teaching students to use English. In the goals of the research, this study discusses the following 
questions:

1) Compared with the traditional method, what are the advantages of the TPR teaching method?

2) Is the TPR teaching method an effective method to teach students? If so, how to use it will be more effective?

\section{B. Participants of the Research}

1. Choice of the Teacher

The teacher is a young woman with four years of teaching experience. Her English is very good, and she is willing to participate in this experiment to improve her teaching ability. She has tried many different methods of teaching in her class. Therefore, there is no doubt that she is a participant.

2. Choice of the Students

In this study, students chosen are from the fourth grade primary students studies in the Experimental primary school of Hongtong County. The reasons for choosing these students as the participants are as follows:

1) English learning of the fourth grade students is regular. A year later in learning English, they have a well learning style, so it is easy to manage them.

2) They have acquired some English knowledge. Compared with the students of grade three, they are the ideal targets of this study.

\section{Research Design}

\section{The Variables of the Experiment}

In this research, independent variable is the two different teaching methods. One is the TPR teaching method, however, the other is the traditional method. TPR teaching method holds that the beginning of the course that should give priority to listening, and then the speaking. Students learn from word to phrase as a method of language learning. There is not much difference between two groups of teaching content, and the teaching content of the two groups will get the same test at the end of the class. In contrast, the traditional methods and means are rote practices involving verbal repetition and practice of spoken language translation, reading activities. Student performance, including their attitudes and the ability to use the target language in the classroom, is related to variables in this study.

2. Experiment Group and Control Group

The experiment is conducted in Experimental primary school of Hongtong County. 20 students are selected from this school. They are all lower grade students at the same level of English proficiency. The content of courses is the same. The only difference is the way to impart knowledge. Teaching by the same person ensures that the teacher's influence is equal. In the course of teaching, each group in the same environment for teaching is used the same evaluation criteria for evaluation. Dividing the students into two groups, one group is the experiment group, the other group is the control group. Each group has the same number of students.

\section{Research Procedure}

\section{Experiment Group}

1.1 General Layout

Ten students in the experimental group are treated with a slightly different environment. That is to say, their desks are not fixed, but move every day to meet the needs of the course. Due to the need of sports, students' desks are usually removed, so that students have more freedom to interact with learning materials.

Since the use of TPR method, students have a lot of chances to touch and see the visual aids. The teacher is ready to give guidance. In order not to confuse the students, she needs to be definite and clear. Furthermore, the teacher should pay more attention to the students' social need and she should create a relaxing and funny atmosphere for the students to complete a part of the course. The teacher prepared in advance, or to provide students with comprehensive listening comprehension, students need to understand. The teacher designs some games, for instance, two students come to the front of the class in pairs, and then one of them performs the action, at the same time, the other person outputs the appropriate language.

1.2 A Typical Course Project: the PPP Model

Presentation: Through watching and listening to the teacher's word, students write it down and explain the word by action or picture. The teacher examines their understanding by performing other actions and asking whether the word they have learned is related to the behavior. Students should be able to use different language input and action to convey to the teacher.

Practice: Students now have the opportunity to practice new words through action, with the teacher's input, and they must decode and respond. In this way, students can remember new words by repeating actions. Once the students are comfortable and familiar with the input of the new vocabulary, the teacher now reverses her dominance and students take up the role of teaching. In this regard, the students are now expressing their hope for the teacher to communicate through words.

Production: Students interact with each other by using new words through competitive games. Teachers can present students with visual input, and students can use their understanding of memory.

In this process, students are required to take an exam to test the students' listening comprehension and the memory of the day's target language. 


\section{Control Group}

\subsection{General Layout}

The teacher must maintain a dominant position on the students in this class. This classroom is dominated by a strict teacher. There is a rigid seat, with the students in a row. The seat does not need to change. This class does not require additional visual aids or special preparation. Teachers use textbooks as a means to convey the information to students. In order to get a target language, students do not need to do special activities in class, the basis for teaching is memory. Such an atmosphere is quiet, diligent, and sometimes oppressive. Students are not active in the classroom, because the atmosphere is very depressed. The teacher gives more work to guide the target language, instead of using the language to speak. Students spend a lot of time on alternative and integrated exercises.

Teachers will focus on the accuracy of the pronunciation of the students. It takes a lot of time to correct students' words. So, students spend more time under the tutor's stress, rather than through the language or actions from the master to use the language. Students spend most of their time in mechanical time, and do not need to fully understand the new vocabulary they have learned.

2.2. A Typical Course Project: Memorizing Mechanically

Beginning: The teacher asks students to come up with their textbooks and find the pages of the new vocabulary. The teacher reads the word, and then students repeat it over and over again until they can recite the pronunciation of the word and the meaning of the word. The teacher asks students to read every word, and then translates the English into Chinese or Chinese to English.

Middle: The teacher gives some examples of the use of new words in sentence structure. The students require to copy the sentences that the teacher makes for them. The teacher then asks the students to use the words they have learned to make a sentence.

End: The teacher takes out the workbook and lets students fill in the blanks with the new words that are learned. Students need to rely on the word to complete the task. The teacher asks students to stand up and give answers, then she checks if they are properly used and pronounced. The interaction between students is very little.

In this process, students are required to take an exam to test the students' ability and the memory of the day's target language.

\section{Results}

In this section, the author makes a detailed analysis about the scores of the experiment group and the control group, and students' response from classroom observation. Two different teaching methods have been put in place since 2 months. The following is a detailed description of the different scores on the same test for the experiment group and the control group. Every exam is a total score of 20 points.

A. The Scores and Analysis of the Experiment Group

TABLE1

THE SCORES OF THE EXPERIMENT GROUP

\begin{tabular}{|c|c|c|c|c|c|c|c|c|c|c|c|}
\hline Students & 1 & 2 & 3 & 4 & 5 & 6 & 7 & 8 & 9 & 10 & Mean \\
\hline Nov. 6th & 20 & 18 & 17 & 19 & 20 & 16 & 17 & 15 & 18 & 20 & 18 \\
\hline Nov. 14th & 17 & 17 & 18 & 16 & 19 & 16 & 15 & 19 & 18 & 19 & 17.4 \\
\hline Nov. 21st & 19 & 19 & 18 & 20 & 20 & 17 & 19 & 17 & 17 & 19 & 18.5 \\
\hline Nov. 28th & 20 & 18 & 17 & 17 & 18 & 19 & 17 & 16 & 18 & 18 & 17.8 \\
\hline Dec. 5th & 20 & 19 & 18 & 19 & 18 & 17 & 17 & 18 & 18 & 19 & 18.3 \\
\hline Dec. 13th & 19 & 18 & 18 & 19 & 20 & 18 & 17 & 17 & 18 & 20 & 18.4 \\
\hline Dec. 20th & 19 & 20 & 19 & 20 & 19 & 18 & 18 & 18 & 19 & 19 & 18.9 \\
\hline Dec. 27th & 20 & 19 & 20 & 20 & 19 & 19 & 18 & 19 & 18 & 20 & 19.2 \\
\hline Average points & 19.25 & 18.5 & 18.13 & 18.75 & 19.13 & 17.5 & 17.25 & 17.38 & 18 & 19.25 & 18.31 \\
\hline
\end{tabular}

Students in the experiment group achieves very good results. In other words, students not only are tested at the end of each lesson, but also there are no extreme differences between students.

These results are consistent with our hypopaper that the experiment group uses TPR method that will provide consistently high results. There are no pressure on the learning environment, and the opportunity to use language. In such a relaxed environment, they will learn better.

\section{B. The Scores and Analysis of the Control Group}


TABLE 2

THE SCORES OF THE CONTROL GROUP

\begin{tabular}{|l|l|l|l|l|l|l|l|l|l|l|l|}
\hline Students & $\mathbf{1}$ & $\mathbf{2}$ & $\mathbf{3}$ & $\mathbf{4}$ & $\mathbf{5}$ & $\mathbf{6}$ & $\mathbf{7}$ & $\mathbf{8}$ & $\mathbf{9}$ & $\mathbf{1 0}$ & Mean \\
\hline Nov. 6th & 14 & 13 & 13 & 10 & 15 & 11 & 17 & 12 & 14 & 18 & 13.7 \\
\hline Nov. 14th & 12 & 14 & 15 & 11 & 15 & 11 & 12 & 17 & 16 & 20 \\
\hline Nov. 21st & 11 & 14 & 10 & 12 & 14 & 12 & 15 & 13 & 13 & 17 & 13.1 \\
\hline Nov. 28th & 9 & 10 & 15 & 9 & 17 & 10 & 17 & 11 & 8 & 16 & 12.2 \\
\hline Dec. 5th & 9 & 11 & 9 & 10 & 14 & 12 & 11 & 12 & 15 & 15 & 11.8 \\
\hline Dec. 13th & 12 & 12 & 13 & 15 & 14 & 13 & 14 & 10 & 11 & 14 & 12.8 \\
\hline Dec. 20th & 14 & 15 & 11 & 15 & 16 & 15 & 14 & 13 & 12 & 16 & 14.1 \\
\hline Dec. 27th & 10 & 11 & 8 & 10 & 11 & 12 & 11 & 14 & 12 & 13 & 11.2 \\
\hline Average points & 11.38 & 12.5 & 11.75 & 11.5 & 14.5 & 12 & 13.88 & 12.75 & 12.63 & 16.13 & 12.9 \\
\hline
\end{tabular}

The average scores of the students in the control group are lower than the average scores of students in the experiment group. There exists some extreme differences between the students' scores. These results are consistent with our hypopaper that the control group uses the rote teaching method that provides wavering results for memory. Stressful learning environment and the lack of language skills are affecting students' learning.

\section{Students'Response from Classroom Observation}

\section{Experiment Group Summary}

In the experiment group, there is a large number of sound and video used in the classroom. The students respond positively to the teacher's suggestion in the classroom. The students have enough time to listen and understand the target words, so they are very confident and seldom worry about making mistakes when they come to speak. Classroom atmosphere is not subdued, it is very lively, the students are also very happy. Students sit face to face to see each other from a distance, and activity occurs in the center of the group. Students do not have to face each others' back, which makes it easier to interact in the target language. In addition, as teachers use the most important target language in classroom communication, students are exposed to the second language in this period. All students want to participate in this activity and are eager to show their behavior. In this way, they can easily produce the second language again.

2. Control Group Summary

In the control group, students spend most of their time in listening and taking notes, without too much visual input, and the contents are taught by the teacher over and over again. Teachers give students little time to find out whether they have acquired the necessary understanding including the words that have been learned. Teachers present a grammar rule in class and students spend a lot of time writing the grammar rules. Next, the students need to complete a grammar exercise. The use of target language for any type of voice interaction spends little time. Students do not have the space to move or perform actions. Students are in the face of the teacher and the blackboard and their seats are fixed. When the students read after teacher over and over again, and spend most of the time on the exercises, the atmosphere is not active and makes them depressed. The output of the students is entirely based on the teacher's example. Students do not appear to stimulate learning, their answer is just to answer the teacher's questions, rather than a positive part of the classroom.

\section{Discussion}

The general goal of the TPR teaching method is to make the students learn to use the language. The initial stage about teaching is to let the students understand the content of the study, and to teach the language through action. However, the traditional English teaching method in our country is to teach grammar, to master the grammar structure, and the final purpose is to test, instead of using the language. This leads to the traditional teaching method into a single and rigid teaching dead end.

Before the experiment, there is little difference between the two groups. But after the teaching experiment, we can see an obvious difference between the experiment group and the control group. From the analysis of the data, in the experiment group, there are no extreme differences between students' scores. However, in the control group, there exists some extreme differences between the students' scores. On the basis of the above analysis, this paper comes to a conclusion that the TPR teaching method is better than the traditional method. There are lots of advantages of the TPR teaching method, as shown below.

1) It helps to arouse students' learning interest and inspires the enthusiasm of students' learning.

2) The TPR teaching method can reduce the pressure of students.

3) The coordination of language and behavior is beneficial to the development of the brain.

4) It can help students to improve their listening and speaking ability.

5) It is memorable. It can help the students to remember the phrases or words. Actions help to strengthen the connections in the brain.

6) It is funny and easy, students enjoy it. It can really improve the mood.

7) This is good for the learners who need to be active in the classroom.

8) It works well for students and adult learners.

9) It can create an authentic language environment. 


\section{CONCLUSION}

This section is a summary of the whole paper, the main results are as follows. On the basis of this research, the writer illustrates some main findings of the research on the teaching of English for students and the limitations of this study, and puts forward some suggestions for further research in this chapter.

In the last section, the author expounds the research data and data analysis. The writer finds that TPR teaching method can obtain better teaching effect than traditional method. The TPR teaching method can arouse students' interest in learning English. The author believes that it is necessary to carry out such a study, in order to give the best way for students to work and to develop their abilities in the target language. The main findings of this study are as follows:

First of all, using TPR teaching method in our study to teach students can make sure students have better listening ability than traditional teaching method. The experiment data about teaching shows that after a period of study, the progress of the experiment group is more obvious than that of the control group through different teaching method, which has been mentioned in the results of testing. Before the experiment, there is not much difference between the two groups. This may be the case, when using the TPR teaching method to teach English, the teacher always asks students in the process of language input to do the actual action with her together. Then the teacher uses a variety of methods to make the students produce language. In this way, students can use more time to speak English. When students say more, they can learn more useful words and expressions. At the same time, it can not only improve their spoken English level, but also promote the improvement of students' listening ability.

In the next place, as we can see, the TPR teaching method is easier for the students to review the knowledge that they have learned than the traditional teaching method. From the analysis of data, the author finds that the scores of the experiment group are significantly higher than those of the control group in these tests. TPR teaching method enables students to use their hands and brain in learning, and stimulate students a variety of senses.

Finally, according to the observation results, the use of TPR teaching method to teach students, learning atmosphere and classroom activity participation are better than the traditional method. The TPR teaching method is also in line with the characteristics of primary students, so that they learn English through the body movements without too much explicit pressure.

Although some important results have been obtained in this research, there are still some shortcomings:

First of all, in this study, due to the limitations of time and energy, this paper chooses 20 students to collect research data. Therefore, the results of this study have certain limitations and can only provide limited suggestions for students' English learning. Secondly, the teaching experiment lasts only 2 months. Many of the anticipated results in such a short period can not be fully mentioned. If the study lasts for a long time, the writer believes that the results will be more accurate and reliable.

In consideration of the limitations of this study, the following researches need to be further studied. Above all, we can further study the TPR teaching method, especially in combination with the characteristics of students' English learning. Next, the scope of the research object can be extended. In this study, the writer chooses the fourth grade students in primary school. We can also choose the students in their third and fifth grade to increase the size of the sample. Under the circumstances, the reliability of the study will be greatly improved. The time of the study can be prolonged, in order to have enough time to investigate larger sample or individual case. If this is the case, in order to improve the students' English, we can provide more valuable suggestions.

\section{REFERENCES}

[1] DeCecco, J. D. (1968). The Psychology of Learning and Instruction: Educational Psychology. Englewood Cliffs, N. J: Prentice-Hall.

[2] Gong Yafu. (2000). TPR English Teaching Method. Beijing: foreign language Teaching and Research Press.

[3] James, J. Asher. (1993). Learning Another Language Through Actions ( $4^{\text {th }}$ Ed). Los Gatos: Sky Oaks Productions.

[4] Krashen, S. D. (2009). Principles and Practice in Second Language Acquisition. Oxford: Pergamon Press.

[5] Wang Li. (2008). Application of TPR Teaching method in Primary School English Teaching. Hei Longjiang: Journal of Heilongjiang Institute of Education, 6, 32-33.

[6] Yu Zhenyou. (1992). Asher's View on second language acquisition and its Teaching method. Shanghai: Foreign language Teaching.

[7] Zhong Jing. (2002). On the cultivation of Interest in Foreign language Learning by TPR Teaching method. Huizhou: Journal of Huizhou University, 8, 56-58.

[8] Zhu Chun. (2000). Psychology of Foreign language Teaching. Shanghai: Shanghai Foreign language Education Press.

Tingting Shi was born in Linfen, China in 1993. She is studying for her master's degree in linguistics in Shanxi Normal University in 2017.

She is currently a student in the school of Shanxi Normal university. Her research interests include pragmatics and social linguistics. 